\title{
Dynamic changes in the morphology of Cryptococcus neoformans during murine pulmonary infection
}

\author{
Marta Feldmesser, ${ }^{1}$ Yvonne Kress ${ }^{2}$ and Arturo Casadevall ${ }^{1,3}$
}

Author for correspondence: Marta Feldmesser. Tel: +1 718430 3730. Fax: +1 7184308701. e-mail: feldmess@aecom.yu.edu

Departments of Medicine, Division of Infectious Diseases ${ }^{1}$, Pathology ${ }^{2}$ and Microbiology and Immunology ${ }^{3}$, Albert Einstein College of Medicine, Bronx, NY 10461, USA
The pathogenesis of Cryptococcus neoformans infection has been studied extensively with respect to inflammatory and pathological changes, but very little information is available regarding the morphology of yeast cells during the course of infection. Electron microscopy of Cryptococcus neoformans in murine pulmonary infection revealed increased cell wall thickness with time, but this difference was only partially accounted for by increases in cell diameter. Cell walls of melanized cells were thicker than those of nonmelanized cells $\mathbf{2} \mathrm{h}$ after infection, and the cell wall of yeast became blacker with time, suggesting that melanization contributes to the increased cell wall thickness. Heterogeneous cell populations emerged, with the appearance of giant forms. While for C. neoformans ATCC strain 24067 (serotype D) the full spectrum of cell sizes were observed, for strains H99 (serotype A) and 3501 (serotype D) cells were divisible into two populations, giant and micro forms. In contrast to cellular heterogeneity, the epitope recognized by a protective mAb on the capsular glucuronoxylomannan (GXM) was found at all times of infection. Immunoelectron microscopy using mAbs to GXM demonstrated reactivity with intracellular structures, suggesting that synthesis of capsular polysaccharide occurs, at least in part, in the cytoplasm. In summary, the results indicate that: (i) the infection is dynamic with respect to yeast cell morphology; (ii) giant cell forms arise in tissue during the course of infection; (iii) cell walls blacken and thicken during the course of infection, consistent with melanin synthesis during infection; and (iv) GXM epitopes are found in the capsule, cell wall and cytoplasm, consistent with intracellular polysaccharide synthesis. The results indicate that the population of $C$. neoformans cells in tissue is in a highly dynamic state, implying that the immune system must confront cells with varying characteristics during the course of infection.

Keywords: yeast, lung, ultrastructure

\section{INTRODUCTION}

Cryptococcus neoformans is the causative agent of cryptococcosis, a life-threatening fungal infection (reviewed by Mitchell \& Perfect, 1995). Cryptococcosis is a relatively frequent complication of late stage HIV infection (Currie \& Casadevall, 1994) and is associated with other immunosuppressed states, such as haemato-

Abbreviations: L-dopa, L-3,4-dihydroxyphenylalanine; GXM, glucuronoxylomannan; IEM, immunoelectron microscopy. logic malignancies, collagen vascular diseases and steroid therapy. C. neoformans infection is believed to be acquired by inhalation of infectious particles (Levitz, 1991). In the immunocompetent host, the infection is often asymptomatic and limited to the lung. However, in patients with impaired immunity, extrapulmonary dissemination to the central nervous system can occur and meningoencephalitis is the most common clinical presentation of cryptococcosis. Cryptococcosis is currently an incurable infection in patients with AIDS because existing therapy does not eradicate the infection 
in the setting of severe immune suppression (Zuger et al., 1986).

C. neoformans infections in both humans and experimental animals are characteristically chronic. The ability of C. neoformans to persist in tissue, even in immunologically intact hosts, is not well understood. There is considerable evidence that the inability of the host to eradicate infection results from interference with host defence mechanisms by the capsular polysaccharide, which can be found in copious amounts in tissue (Casadevall \& Perfect, 1998). However, it is also possible that the C. neoformans population in host tissue undergoes changes that contribute to the inability of the host immune response to clear the infection. For other pathogens, antigenic variation is an important mechanism for evasion of host defences. Recently, $C$. neoformans has been shown to be able to undergo reversible cellular morphological changes by phenotypic switching in vitro and, possibly, in vivo (Goldman et al., 1998). For C. neoformans cells, several ultrastructural studies have provided highly detailed information on the cellular structure, cell wall and capsule (Al-Doory, 1971; Cassone et al., 1974; Mochizuki et al., 1987; Sakaguchi et al., 1993). From analysis of freeze-etched samples, increases in cell wall thickness, cell body size, capsule size and secretory vacuole activity have been noted in comparisons of yeast in vivo and in vitro (Sakaguchi et al., 1993; Takeo et al., 1973). However, relatively little information is available on the ultrastructure of C. neoformans cells during progressive tissue infection, or the site of synthesis of the capsular polysaccharide.

We recently completed a detailed ultrastructural study of pathology and the host response in murine pulmonary cryptococcal infection (Feldmesser et al., 2000a). That study focused on identification of the location of $C$. neoformans replication in tissue and established that this yeast is a facultative intracellular pathogen in murine pulmonary infection. During the completion of that study, we noted differences with time in the morphology of C. neoformans cells in the lungs of infected mice. The availability of tissue sections from various stages of infection allowed us to ask if the morphology of the yeast cell changed during the course of infection. Here, we report on the yeast cell morphological changes associated with chronic infection. We analysed changes during the course of infection in yeast cell size, cell wall thickness and in the appearance of the cell wall by light microscopy. Further, we performed immunoelectron microscopy (IEM) using closely related $\mathrm{mAbs}$ that bind glucuronoxylomannan (GXM), the major component of the capsular polysaccharide, which demonstrated differences in intracellular binding patterns within serotype D strains and provided insight into sites of polysaccharide synthesis. The results indicate that the morphology of yeast cells varies during infection, implying the occurrence of dynamic changes that may contribute to the ability of this organism to persist in tissue.

\section{METHODS}

C. neoformans. ATCC strain 24067 (serotype D) was used for most experiments because it has been used in previous studies of pulmonary pathology (Feldmesser et al., 1998; Feldmesser \& Casadevall, 1997). Limited experiments were done using the acapsular strain Cap 67, its parent strain 3501 (serotype D) (Jacobson \& Tingler, 1994) and H99 (serotype A), the type strain for C. neoformans var. grubii (Franzot et al., 1999). Isolates were maintained at $-80^{\circ} \mathrm{C}$. Cultures were started by inoculation of Sabouraud dextrose broth (Difco) with a loopful of frozen stock and incubated for $48 \mathrm{~h}$ at $30^{\circ} \mathrm{C}$ with moderate shaking. For one experiment designed to look at the appearance of yeast melanized in vitro, C. neoformans was grown in a defined minimal medium $(15 \mathrm{mM}$ glucose, $10 \mathrm{mM}$ $\mathrm{MgSO}_{4}, 13 \mathrm{mM}$ glycine, $3.0 \mu \mathrm{M}$ vitamin $\left.\mathrm{B}_{1}, \mathrm{pH} 5.5\right)$ with or without $1.0 \mathrm{mM}$ L-dopa (Sigma) at $30^{\circ} \mathrm{C}$ for $13 \mathrm{~d}$. Cultures were washed three times in sterile phosphate-buffered saline, counted using a haemocytometer, and the count was confirmed by plating on Sabouraud dextrose agar. One culture of yeast grown and prepared in this manner was fixed in Trump's fixative $(4 \%$ paraformaldehyde and $1 \%$ glutaraldehyde in $0 \cdot 1 \mathrm{M}$ phosphate buffer) and prepared for EM, as described below.

Murine infection. Specific pathogen-free C57BL/6, BALB/c and $\mathrm{A} / \mathrm{JCr}$ mice were obtained from the National Cancer Institute (Bethesda, MD, USA); 129/SvEv mice were obtained from Taconic Farms (Germantown, NY, USA). Within each experiment, mice were of the same sex. Six to 10 week old mice were anaesthetized with $65 \mathrm{mg}$ sodium pentobarbital $\mathrm{kg}^{-1}$ and inoculated intratracheally with $10^{4}$ or $10^{6}$ organisms in $0.05 \mathrm{ml}$ sterile PBS via a midline neck incision using a bent 26 gauge needle attached to a tuberculin syringe. The incision was then sutured with 5-0 silk (Feldmesser \& Casadevall, 1997). The higher inoculum was used for experiments in which mice were killed prior to $24 \mathrm{~h}$ after infection to facilitate visualization of yeast cells in tissue by EM. The lower inoculum was used for experiments in which mice were killed $24 \mathrm{~h}$ or later after infection, except where stated. In the following sets of experiments, mice of the strain indicated in parentheses were infected concurrently with strain 24067, except where indicated, and were killed at: (i) $5 \mathrm{~min}$ or $2 \mathrm{~h}$ after infection (BALB/c); (ii) $24 \mathrm{~h}, 48 \mathrm{~h}, 7 \mathrm{~d}$ or $28 \mathrm{~d}$ after infection (C57BL/6); (iii) $13 \mathrm{~d}$ after infection with $10^{4}$ or $10^{6}$ yeast cells $(129 / \mathrm{SvEv})$; (iv) $14 \mathrm{~d}$ after infection (A/JCr); (v) $14 \mathrm{~d}$ after infection (C57/BL6); (vi) $24 \mathrm{~h}$ after infection with strains 24067, Cap 67 or 3501 (C57/BL6); (vii) $14 \mathrm{~d}$ after infection with strain 3501 (C57/BL6); (viii) $2 \mathrm{~h}$ or $14 \mathrm{~d}$ after infection with strain H99 (C57/BL6); and (ix) $2 \mathrm{~h}$ after infection with strain 24067 grown in minimal medium with or without L-dopa (C57/BL6). In each experiment, two mice were studied for each group. Overall, this study includes data from 36 mice. At the times indicated in individual experiments, mice were killed by cervical dislocation. Their lungs were removed and fixed in Trump's fixative for EM.

Microscopy. For EM, tissue blocks and cells were post-fixed with $1 \%$ osmium for $1 \mathrm{~h}$, dehydrated in ascending ethanol $(30-100 \%)$, cleared in two changes of acetonitrile, and then infiltrated with and embedded in araldite-epon, as described by Feldmesser et al. (1997). After light microscopic review of $1 \mu \mathrm{m}$ toluidine-blue-stained sections, ultrathin sections of selected regions were stained with uranyl acetate and lead citrate and examined with a JEOL 100 S or 100 CX electron microscope. A minimum of five noncontiguous grids were imaged for each mouse and the data were pooled for analysis. At least $22 \%$ of the yeast cell measurements came from each 
Table 1. Cell wall thickness of C. neoformans strain 24067 in vitro and at various times of infection

\begin{tabular}{|c|c|c|c|c|c|c|}
\hline \multirow[t]{3}{*}{ Condition } & \multicolumn{4}{|c|}{ Cell wall thickness" } & \multicolumn{2}{|c|}{$\begin{array}{l}\text { Mean cell wall thickness/cell } \\
\text { diameter }\end{array}$} \\
\hline & \multirow{2}{*}{ Mean \pm SD $(n) \dagger$} & \multirow{2}{*}{ Median } & \multirow{2}{*}{ Range } & \multirow{2}{*}{$P \neq$} & & \\
\hline & & & & & $\pm \mathrm{SD}(\boldsymbol{n})+\mathbb{S}$ & $P \neq$ \\
\hline In vitro & $0 \cdot 05 \pm 0 \cdot 02(23)$ & $0 \cdot 05$ & $0 \cdot 03-0 \cdot 12$ & - & $0 \cdot 021 \pm 0 \cdot 007(24)$ & - \\
\hline $5 \mathrm{~min}$ & $0 \cdot 14 \pm 0 \cdot 09(23)$ & $0 \cdot 13$ & $0 \cdot 04-0 \cdot 36$ & $\begin{array}{l}P_{1}<0.0001 \\
P_{2}=0.02\end{array}$ & $0 \cdot 048 \pm 0 \cdot 020(17)$ & $\begin{array}{l}P_{1}<0.0001 \\
P_{2}=0.008\end{array}$ \\
\hline $2 \mathrm{~h}$ & $0 \cdot 10 \pm 0 \cdot 05(37)$ & $0 \cdot 09$ & $0 \cdot 03-0 \cdot 20$ & $P_{1}^{2}<0.0001$ & $0 \cdot 033 \pm 0 \cdot 015(27)$ & $P_{1}^{2}=0.0004$ \\
\hline $24 \mathrm{~h}$ & $0 \cdot 19 \pm 0 \cdot 14(56)$ & $0 \cdot 17$ & $0 \cdot 04-0 \cdot 80$ & $P_{2}<0.005$ & $0 \cdot 045 \pm 0 \cdot 018$ & $P_{2}=0 \cdot 02$ \\
\hline $48 \mathrm{~h}$ & $0 \cdot 21 \pm 0 \cdot 15(75)$ & $0 \cdot 17$ & $0 \cdot 03-0 \cdot 67$ & $P_{2}<0.005$ & $0 \cdot 061 \pm 0 \cdot 026(21)$ & $P_{2}=0.0002$ \\
\hline $7 \mathrm{~d}$ & $0 \cdot 22 \pm 0 \cdot 12(73)$ & $0 \cdot 20$ & $0 \cdot 06-0 \cdot 60$ & $P_{2}<0.005$ & $0 \cdot 064 \pm 0 \cdot 025(21)$ & $P_{2}<0.0001$ \\
\hline $13-14 \mathrm{~d}$ & $0 \cdot 21 \pm 0 \cdot 13(108)$ & $0 \cdot 17$ & $0 \cdot 04-0.67$ & $P_{2}<0.005$ & $0 \cdot 061 \pm 0 \cdot 028$ & $P_{2}<0.0001$ \\
\hline $28 \mathrm{~d}$ & $0 \cdot 25 \pm 0 \cdot 14(107)$ & $0 \cdot 20$ & $0 \cdot 06-1 \cdot 00$ & $P_{2}<0.005$ & $0 \cdot 085 \pm 0 \cdot 026(12)$ & $P_{2}<0.0001$ \\
\hline $2 \mathrm{~h}$ nonmelanized & $0 \cdot 10 \pm 0 \cdot 03(23)$ & $0 \cdot 10$ & $0 \cdot 07-0 \cdot 17$ & - & $\mathrm{ND}$ & - \\
\hline $2 \mathrm{~h}$ melanized & $0 \cdot 16 \pm 0 \cdot 04(24)$ & $0 \cdot 15$ & $0 \cdot 08-0 \cdot 25$ & $P_{3}<0 \cdot 001$ & $\mathrm{ND}$ & - \\
\hline
\end{tabular}

ND, Not done.

* Mean, median and range values in $\mu \mathrm{m}$.

$\dagger n$, Number in parentheses is the number of measurements.

$\ddagger P$ values calculated by $t$-test after analysis of variance. $P_{1}$ corresponds to the comparison with yeast cells fixed following in vitro culture in Sabouraud's dextrose broth. $P_{2}$ corresponds to the comparison versus the $2 \mathrm{~h}$ group, for which the inocula were grown in Sabouraud's dextrose broth. With the Bonferroni correction for multiple comparisons, significance is defined by a $P$ value $\leqslant 0 \cdot 006$. $P_{3}$ refers to comparison between cells grown in minimal medium alone (nonmelanized) and with L-dopa (melanized) studied $2 \mathrm{~h}$ after murine infection.

SFor some groups, the $n$ differs from that used for cell wall thickness measurements as cells for which the entire cell was not visible were excluded.

mouse, except for the 13-14 d determinations, where $7-37 \%$ of the values came from each of the four experiments. Cell wall measurements were limited to yeast cells where the sectioning occurred near the equatorial plate, as indicated by sharp cell wall edges. For intracellular localization of cryptococcal capsular polysaccharide using immunogold, immunohistochemistry was performed using mAbs 2H1 (IgG1), 12A1 (IgM) or $13 \mathrm{~F} 1$ (IgM), murine mAbs that bind the GXM component of the polysaccharide, as described by Casadevall et al. (1998) and Feldmesser et al. (2000b). Ultrathin lung tissue sections on nickel grids were incubated in $10 \% \mathrm{H}_{2} \mathrm{O}_{2}$ for $10 \mathrm{~min}$, washed in PBS, then etched in a saturated solution of sodium periodate for $10 \mathrm{~min}$, washed in PBS and blocked with $2 \%$ goat serum for $1 \mathrm{~h}$. Grids were incubated overnight in $5 \mu \mathrm{g}$ primary $\mathrm{mAb} \mathrm{ml} \mathrm{l}^{-1}$ in $2 \%$ goat serum at $4{ }^{\circ} \mathrm{C}$. As a control, grids were incubated in murine IgG1 (Sigma) or PC-140, an IgM mAb that binds phosphorylcholine (IgM) (Thammana \& Scharff, 1983). Grids were washed in PBS with $2 \%$ goat serum with $0 \cdot 1 \%$ gelatin (60 Bloom units) and $0 \cdot 01 \%$ Tween 20 and then incubated in biotin-conjugated goat anti-mouse IgG1 or IgM $\left(2 \cdot 5 \mu \mathrm{g} \mathrm{ml}^{-1}\right)$ (Southern Biotechnology Associates) for $1 \mathrm{~h}$. After washing, grids were incubated in $10 \mathrm{~nm}$ gold conjugated to streptavidin (Goldmark Biologicals) diluted $1: 30$ in $1 \%$ bovine serum albumin for $2 \mathrm{~h}$ at room temperature, washed and fixed in $2 \%$ glutaraldehyde. When comparisons were made between C. neoformans strains or for labelling of the same strain with different mAbs, immunolabelling of samples was performed concurrently. Labelling of all samples was performed at least twice.

Data analyses were performed using the Excel spreadsheet software package. After analysis of variance, pairwise com- parison was performed using the Student's $t$-test. The alpha level was adjusted using the Bonferonni correction.

\section{RESULTS}

Yeast cell diameter, cell wall thickness, capsule volume and cell volume were measured at $5 \mathrm{~min}, 2 \mathrm{~h}, 24 \mathrm{~h}, 48 \mathrm{~h}$, $7 \mathrm{~d}, 14 \mathrm{~d}$ and $28 \mathrm{~d}$ infection (Table 1 and Table 2). We also measured the cell wall thickness of melanized $C$. neoformans instilled into murine lungs at $2 \mathrm{~h}$ of infection and of $C$. neoformans cells prepared as the infecting inocula (Table 1). Pairwise comparison showed no difference in the values obtained from mice within individual experiments, except for mice studied $28 \mathrm{~d}$ after infection (data not shown). Both the yeast cell wall thickness and mean yeast cell diameter (excluding capsule) of cells prepared as for infecting inocula were smaller than those of yeast cells $5 \mathrm{~min}$ after infection. The yeast cell diameter was the same at $5 \mathrm{~min}$ and $2 \mathrm{~h}$ after infection, a finding that presumably reflects the fact that at $2 \mathrm{~h}$ infection, most of the yeast cells in the lung originate from the infecting inoculum. The ratio of cell wall thickness to cell diameter was lower in the infecting inoculum than at $5 \mathrm{~min}$, demonstrating that the difference in cell wall thickness was not solely a function of yeast cell size. After $2 \mathrm{~h}$, the mean and median cell wall thickness of $C$. neoformans increased with age of infection until the day 28 measurement. At least in part, this increase in cell wall thickness reflects an increase in 
Table 2. Summary of measurements of C. neoformans strain 24067 cells

$n$ refers to the number of measurements.

\begin{tabular}{|c|c|c|c|c|c|}
\hline Condition & $\begin{array}{c}\text { Total cell } \\
\text { diameter }(\mu \mathrm{m})\end{array}$ & $\begin{array}{c}\text { Total cell } \\
\text { volume* }^{*}\left(\mu \mathrm{m}^{3}\right)\end{array}$ & $\begin{array}{c}\text { Yeast cell } \\
\text { diameter }(\mu \mathrm{m})\end{array}$ & $\begin{array}{c}\text { Yeast cell } \\
\text { volume }^{*}\left(\mu \mathrm{m}^{3}\right)\end{array}$ & $\begin{array}{c}\text { Capsule } \\
\text { volume } \dagger\left(\mu \mathrm{m}^{3}\right)\end{array}$ \\
\hline In vitroł & ND & ND & $\begin{array}{c}2 \cdot 52 \pm 0 \cdot 46 \mathbb{S} \\
n=24\end{array}$ & $\begin{array}{c}9 \cdot 25 \pm 4 \cdot 84 \mathbb{S} \\
n=24\end{array}$ & ND \\
\hline $5 \mathrm{~min}$ & $\begin{array}{c}4 \cdot 51 \pm 0 \cdot 78 \\
n=17\end{array}$ & $\begin{array}{c}52 \cdot 9 \pm 28 \cdot 7 \\
n=17\end{array}$ & $\begin{array}{c}3 \cdot 07 \pm 0 \cdot 58 \\
n=17\end{array}$ & $\begin{array}{c}16 \cdot 6 \pm 9 \cdot 4 \\
n=17\end{array}$ & $\begin{array}{c}36 \cdot 2 \pm 24 \cdot 6 \\
n=17\end{array}$ \\
\hline $2 \mathrm{~h}$ & $\begin{array}{c}5 \cdot 12 \pm 1 \cdot 73 \\
n=10\end{array}$ & $\begin{array}{c}92 \cdot 9 \pm 79 \cdot 8 \\
n=10\end{array}$ & $\begin{array}{c}3 \cdot 25 \pm 0 \cdot 90 \\
n=10\end{array}$ & $\begin{array}{c}22 \cdot 0 \pm 19 \cdot 5 \\
n=10\end{array}$ & $\begin{array}{r}70 \cdot 9 \pm 65 \\
n=10\end{array}$ \\
\hline $24 \mathrm{~h}$ & $\begin{array}{c}9 \cdot 79 \pm 3 \cdot 10 \\
n=16\end{array}$ & $\begin{array}{c}624 \pm 424 \mathbb{S} \\
n=16\end{array}$ & $\begin{array}{c}4 \cdot 81 \pm 1 \cdot 41 \\
n=16\end{array}$ & $\begin{array}{c}72 \cdot 0 \pm 52 \cdot 6 \\
n=16\end{array}$ & $\begin{array}{c}563 \pm 438 \mathbb{S} \\
n=16\end{array}$ \\
\hline $48 \mathrm{~h}$ & $\begin{array}{c}11 \cdot 1 \pm 7 \cdot 0 \\
n=19\end{array}$ & $\begin{array}{c}1478 \pm 1818 \\
n=23\end{array}$ & $\begin{array}{c}4 \cdot 26 \pm 2 \cdot 52 \\
n=23\end{array}$ & $\begin{array}{c}87 \cdot 7 \pm 140 \\
n=23\end{array}$ & $\begin{array}{c}1390 \pm 1731 \\
n=23\end{array}$ \\
\hline $7 \mathrm{~d}$ & $\begin{array}{c}4 \cdot 66 \pm 2 \cdot 1 \\
n=20\end{array}$ & $\begin{array}{c}89 \cdot 7 \pm 126 \\
n=20\end{array}$ & $\begin{array}{c}2 \cdot 67 \pm 1 \cdot 01 \\
n=20\end{array}$ & $\begin{array}{r}14 \cdot 5 \pm 22 \\
n=20\end{array}$ & $\begin{array}{l}75 \pm 170 \\
n=20\end{array}$ \\
\hline $14 \mathrm{~d}$ & $\begin{array}{c}3 \cdot 59 \pm 2 \cdot 57 \\
n=22\end{array}$ & $\begin{array}{c}259 \pm 263 \\
n=22\end{array}$ & $\begin{array}{c}4 \cdot 25 \pm 1 \cdot 61 \\
n=22\end{array}$ & $\begin{array}{r}60 \cdot 1 \pm 95 \\
n=22\end{array}$ & $\begin{array}{c}198 \pm 243 \\
n=22\end{array}$ \\
\hline $28 \mathrm{~d}$ & $\begin{array}{c}14 \cdot 0 \pm 7 \cdot 1 \\
n=10\end{array}$ & $\begin{array}{c}2396 \pm 2383 \mathbb{\$} \\
n=10\end{array}$ & $\begin{array}{c}5 \cdot 6 \pm 2 \cdot 26 \\
n=10\end{array}$ & $\begin{array}{c}132 \pm 119 \\
n=10\end{array}$ & $\begin{array}{c}2263 \pm 2282 \mathbb{S} \\
n=10\end{array}$ \\
\hline
\end{tabular}

*Volumes were calculated based upon the measured diameters.

† Capsule volume was calculated by subtracting the yeast cell volume from the total cell volume.

$\ddagger$ The in vitro condition refers to measurements made for C. neoformans grown in Sabouraud's dextrose broth. Total cell measurements were not done (ND) because the capsule was not preserved following sample processing.

\Denotes statistically significant difference from the corresponding measurement at $2 \mathrm{~h}$ by Student's $t$-test using the Bonferroni correction $(P<0 \cdot 007)$.

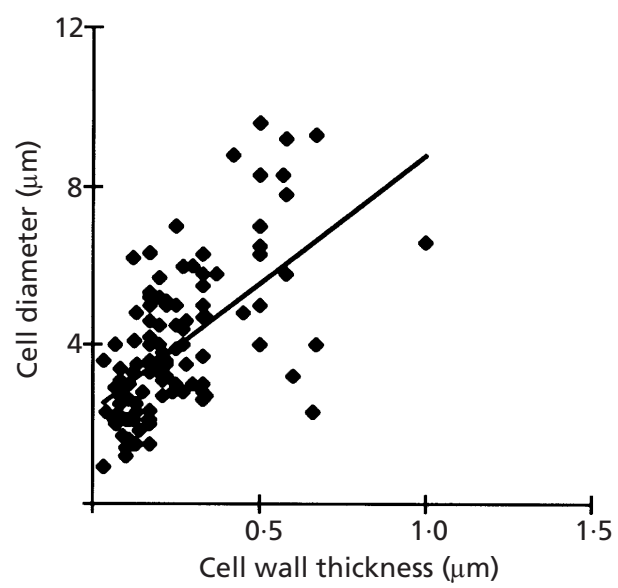

Fig. 1. Cell wall thickness as a function of cryptococcal cell diameter. Each point $(n=117)$ represents one organism of strain 24067 obtained from mice infected for times ranging from $2 \mathrm{~h}$ through $28 \mathrm{~d}$. The linear trendline demonstrates the direct relationship between cell wall thickness and cell diameter.

the size of the yeast cell diameter, as the cell wall thickness varied directly with yeast cell diameter (Fig. 1). However, to account for possible proportional increases in cell wall thickness in relation to cell size, the cell wall diameter was also divided by the cell diameter. This ratio increased from $2 \mathrm{~h}$ through $28 \mathrm{~d}$, and was significantly higher than the $2 \mathrm{~h}$ value at all times from 48 h onward. Thus, the mean cell wall thickness of $C$. neoformans increased as a function of time of infection and was not simply the result of increased cell size. The data for 13-14 d after infection shown in Table 1 were pooled from four experiments using three mouse strains. There was no difference in the values obtained from the two experiments that used C57/BL6 mice, or between $\mathrm{A} / \mathrm{JCr}$ and $129 / \mathrm{SvEv}$ mice infected with $10^{4}$ or $10^{6}$ yeast cells. However, both yeast cell wall thickness and the ratio of cell wall thickness to yeast cell diameter were significantly higher in C57/BL6 mice than in A/JCr and $129 / S_{v E v}$ mice (data not shown). Still, comparison of data from each of these individual experiments to those from $2 \mathrm{~h}$ after infection showed a significant increase in cell wall thickness.

Since C. neoformans cells reportedly melanize during murine infection (Nosanchuk et al., 1999), we hypothesized that the increase in cell wall thickness might be related to melanization. To evaluate this possibility, melanized cells obtained by growing C. neoformans in minimal medium with L-dopa were inoculated in the lungs and cell wall thickness was measured. The cell 

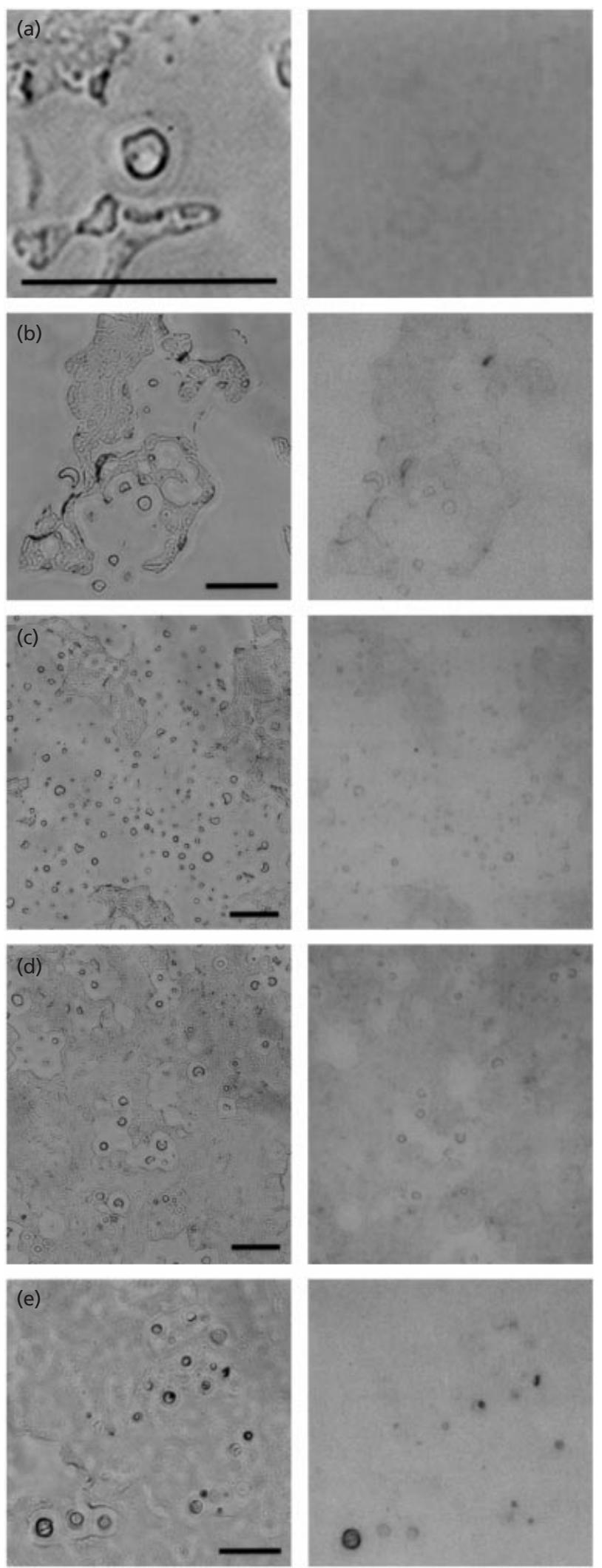

Fig. 2. Appearance of $C$. neoformans strain 24067 in unstained $1 \mu \mathrm{m}$ lung sections obtained at different times after infection, demonstrating yeast with progressively darker cell walls, which appear blacker in colour images. Panels on the right are the wall thickness of melanized cells in lung tissue $2 \mathrm{~h}$ after intratracheal inoculation was significantly larger than that of cells grown in minimal medium without L-dopa. To obtain additional evidence for melanization in tissue as an explanation for cell wall thickness, we evaluated the cell wall for colour changes in unstained tissue sections by light microscopy. With increasing time after infection with nonmelanized cells, the cryptococcal cell wall became progressively blacker (Fig. 2).

In addition to changes in cell wall thickness, we noted the appearance of a heterogeneous cell population during the course of infection. A striking observation was the appearance of giant C. neoformans cells in infected lung tissue $24 \mathrm{~h}$ after infection (Fig. 3). These cells ranged up to $28 \mu \mathrm{m}$ in diameter. Giant C. neoformans cells were found almost exclusively in the extracellular space. At all times of infection after $2 \mathrm{~h}$, there was a wide range in the diameter of yeast cells that represented the full spectrum of sizes between the smallest and the giant forms. Similarly, increases in range of size and variance between cells were found in total yeast volume and capsule volume (Table 2). At all times of infection, there were C. neoformans cells with capsule dimensions corresponding to those measured at $5 \mathrm{~min}$ and $2 \mathrm{~h}$. In contrast, examination of cells prepared as the infecting inoculum showed that of 317 yeast examined on low magnification fields $(\times 7500)$, no yeast had a cell diameter $>3.3 \mu \mathrm{m}$ (range: $1 \cdot 1-3.3 \mu \mathrm{m}$ ). Thus, the appearance of giant cells was not the result of size heterogeneity of the infecting inoculum. These observations indicate that $C$. neoformans pulmonary infection in mice is associated with the emergence of heterogeneous yeast cell populations remarkable for a range of cell and capsule size.

To establish whether the observations made with strain 24067 were applicable to serotype A strains, mice were infected with strain $\mathrm{H} 99$ and lung sections were studied at $2 \mathrm{~h}$ and $14 \mathrm{~d}$ after infection. For strain H99, the mean cell wall thickness did not significantly increase during infection (mean cell wall thickness at $2 \mathrm{~h}$ was $0 \cdot 20 \pm 0 \cdot 04$ vs $0.31 \pm 0.3 \mu \mathrm{m}$ at $14 \mathrm{~d} ; P=0.269 ; n=12$ for $2 \mathrm{~h}, n=$ 48 for $14 \mathrm{~d}$ measurement). However, unlike strain 24067, which produced yeast cells representing the continuum of cell size between smaller and giant forms, for strains H99 and a second serotype D strain (3501), two more discrete populations emerged that could be divided into two groups - giant and micro forms. Examination of $1 \mu \mathrm{m}$ toluidine-blue-stained sections demonstrated that at $14 \mathrm{~d}$ after infection, the mean percentage of yeast that were giant forms was $69 \cdot 7 \pm 20 \cdot 3 \%$ and $70 \cdot 5 \pm 27 \cdot 4 \%$ for strains H99 and 3501, respectively (for H99, 20 fields were counted at a magnification of $\times 200$; for 3501,13 fields were counted). Because the cell wall thickness of many micro forms of strain H99 was smaller than that

phase-contrast images of the panels on the left, which were imaged using standard optics. Times after infection: (a) $24 \mathrm{~h}$; (b) $48 \mathrm{~h}$; (c) $7 \mathrm{~d}$; (d) $14 \mathrm{~d}$; (e) $28 \mathrm{~d}$. Bars, $10 \mu \mathrm{m}$. 

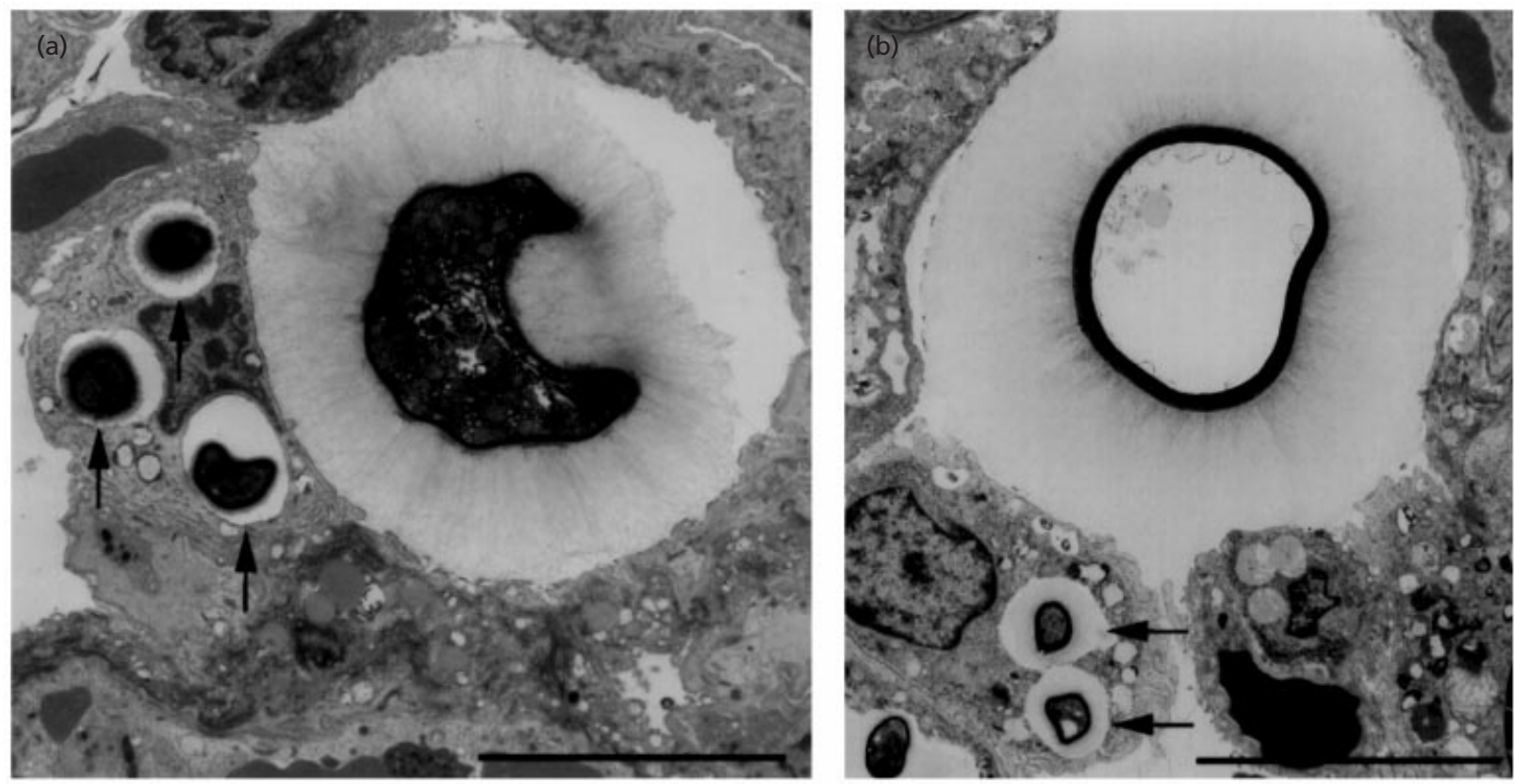

Fig. 3. Giant and smaller C. neoformans cells coexist in tissue. (a) Strain 3501, $24 \mathrm{~h}$ after infection. (b) Strain $24067,48 \mathrm{~h}$ after infection. Bars, $10 \mu \mathrm{m}$. Arrows point to smaller intracellular yeast.
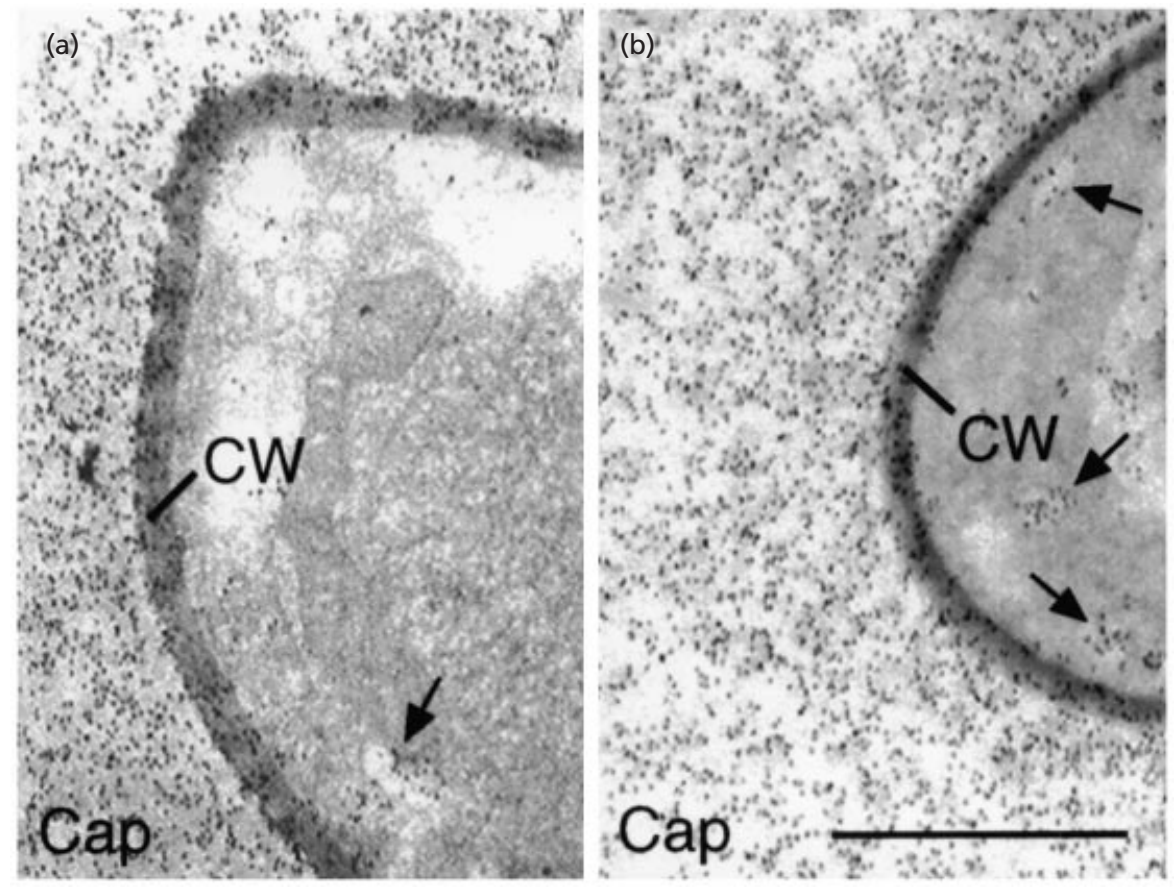

Fig. 4. Intracellular location of epitope for the capsular polysaccharide. Immunogold labelling with mAb $12 \mathrm{~A} 1$ demonstrated labelling of the cell wall and cytoplasmic vesicles in addition to the capsule. (a, b) Micrographs shown are from mice infected for $48 \mathrm{~h}$ with C. neoformans strain 24067. Cap, capsule; CW, cell wall. Arrows point to cytoplasmic vesicles containing gold particles. Bar, $1 \mu \mathrm{m}$.

seen at $2 \mathrm{~h}$, measurement of the two populations yielded a mean cell wall thickness that was not significantly different.
The availability of tissue sections from different times of infection allowed us to investigate whether the epitope recognized by protective antibodies was expressed at all 
times of infection. Labelling of cells from tissue obtained from mice infected from $2 \mathrm{~h}$ through $28 \mathrm{~d}$ demonstrated the presence of gold particles in all three locations. Unexpectedly, this study also provided information on the site of capsule synthesis, since it appeared that in some yeast, there was intracellular immunogold staining in addition to that found in the capsule structure, as expected. To study the location of capsule synthesis, immunogold labelling with mAb $2 \mathrm{H} 1$ was performed on lung tissue obtained from mice infected with strain 24067 for times ranging from $2 \mathrm{~h}$ through $28 \mathrm{~d}$. IEM demonstrated the presence of the epitope not only in the capsule, but also in the cryptococcal cell wall and cytoplasm (Fig. 4), where it appeared to be localized primarily to membrane-bound vacuolar structures. For tissue obtained from mice infected for $48 \mathrm{~h}$, the same pattern of labelling was seen when the IgM mAbs $12 \mathrm{~A}$ and 13F1 were used. For strain 3501, labelling of tissue from mice infected for $24 \mathrm{~h}$ with mAb $13 \mathrm{~F} 1$ produced a pattern and intensity of labelling comparable to that seen for strain 24067 (Fig. 5). However, both mAbs 2H1 and 12A1 labelled both the capsule and intracellular locations of strain 3501 less intensely than for strain 24067. To determine whether the epitope was present in acapsular cells, immunogold labelling of Cap 67 was performed. For Cap 67, only occasional gold particles were present when $\mathrm{mAbs} 2 \mathrm{H} 1$ or $12 \mathrm{~A} 1$, which bind the same epitope, were used. However, for mAb 13F1, gold label was present in the cell wall. Very rare gold particles were present on sections from all three strains labelled with the control IgG or PC-140 Abs, or on sections of normal lung from mice infected for 5 min labelled with $\mathrm{mAb} 13 \mathrm{~F} 1$, indicating that labelling was specific.

\section{DISCUSSION}

The goal of this study was to establish whether the characteristics of yeast cells changed during the course of murine C. neoformans pulmonary infection and to identify yeast cellular characteristics that may provide insight into the mechanism by which C. neoformans establishes chronic infections that are ultimately lethal to mice. The results reveal a highly dynamic process whereby major changes occur in C. neoformans cells during the course of experimental murine infection. Morphological changes are potentially relevant to cryptococcal pathogenesis because they suggest the possibility that, in vivo, new cellular forms arise from selection and/or changes stimulated by the growth in tissue conditions. The generation of new variants that present different problems to host immune effector cells may contribute to persistent infection.

Cell wall thickening occurred early in the course of infection and was maintained during chronic infection. These results confirm the work of Sakaguchi et al. (1993), who reported that the cell wall of C. neoformans in tissue is thicker than that of cells grown in vitro. However, we extended that finding by showing that the increase in cell wall thickness is maintained following normalization for changes in cell diameter, thus rigorously demonstrating a progressive thickening of the cell wall during infection. We hypothesized that a mechanism for the increased cell wall thickness was melanization in vivo, given recent evidence that $C$. neoformans cells synthesize melanin during infection (Nosanchuk et al., 1999). To evaluate this possibility, we compared the cell wall thickness of melanized and nonmelanized cells. C. neoformans cells grown in medium with L-dopa had significantly thicker cell walls than did nonmelanized cells, demonstrating that melanization increases cell wall thickness. The finding that melanization of C. neoformans cells in vivo is progressive and takes several days is consistent with the timing of the increase in cell wall thickness observed in this study. Since there has been some controversy regarding the extent of in vivo melanization (Liu et al., 1999), we sought to obtain additional evidence that this process was in fact occurring in our system. Light microscopic analysis of unstained tissue sections revealed that cryptococcal cell walls became progressively darker during the course of infection, a finding that we attribute to melanin formation. Though melanin in the cryptococcal cell wall is probably amorphous (Nosanchuk et al., 1999), the presence of this additional material may cause the observed increased cell wall thickness. A melanized cell wall may serve a protective role by shielding the yeast cell from host antimicrobial substances (Wang \& Casadevall, 1994).

In evaluating cell wall thickness, we considered the sources of error that can impact on measurement. The first potential source of error results from measurement of sectioned images of cells that are approximately spherical, as measurements of cell wall thickness in cells sectioned near the pole would yield larger values than measurements of cells sectioned near the equator. Therefore, we only measured cells with cell walls that both appeared sharp and had relatively constant thickness throughout the circumference of the cell. We avoided cells with blurred edges, which arise from sectioning near the pole, and those with varying thickness, which result from sectioning on a plane that is not perpendicular to the cross-section of the cell. The second potential source of error comes from averaging the size and shape of a cell population that is not normally distributed. For strain 24067 , cell size appeared to be continuous, whereas for H99, there clearly were two populations of cells that differed sharply in size. For H99, averaging the cell walls of all cells imaged did not result in a statistically significant increase in size because of the increased variance introduced by measurements of giant cells. A third potential source of error is cell wall changes introduced by fixation, staining and processing of tissue. We noted that the cell wall thickness changed when comparing cells in culture to those from tissue 5 min after infection. The ratio of cell wall thickness to cell diameter in the infecting inoculum was the same as that at $2 \mathrm{~h}$, a finding that may reflect osmotic differences between culture conditions and the lung, or an initial rapid alteration in yeast in response to infection. Alternatively, the difference in cell wall thickness noted between cells fixed from in vitro culture and from tissue 

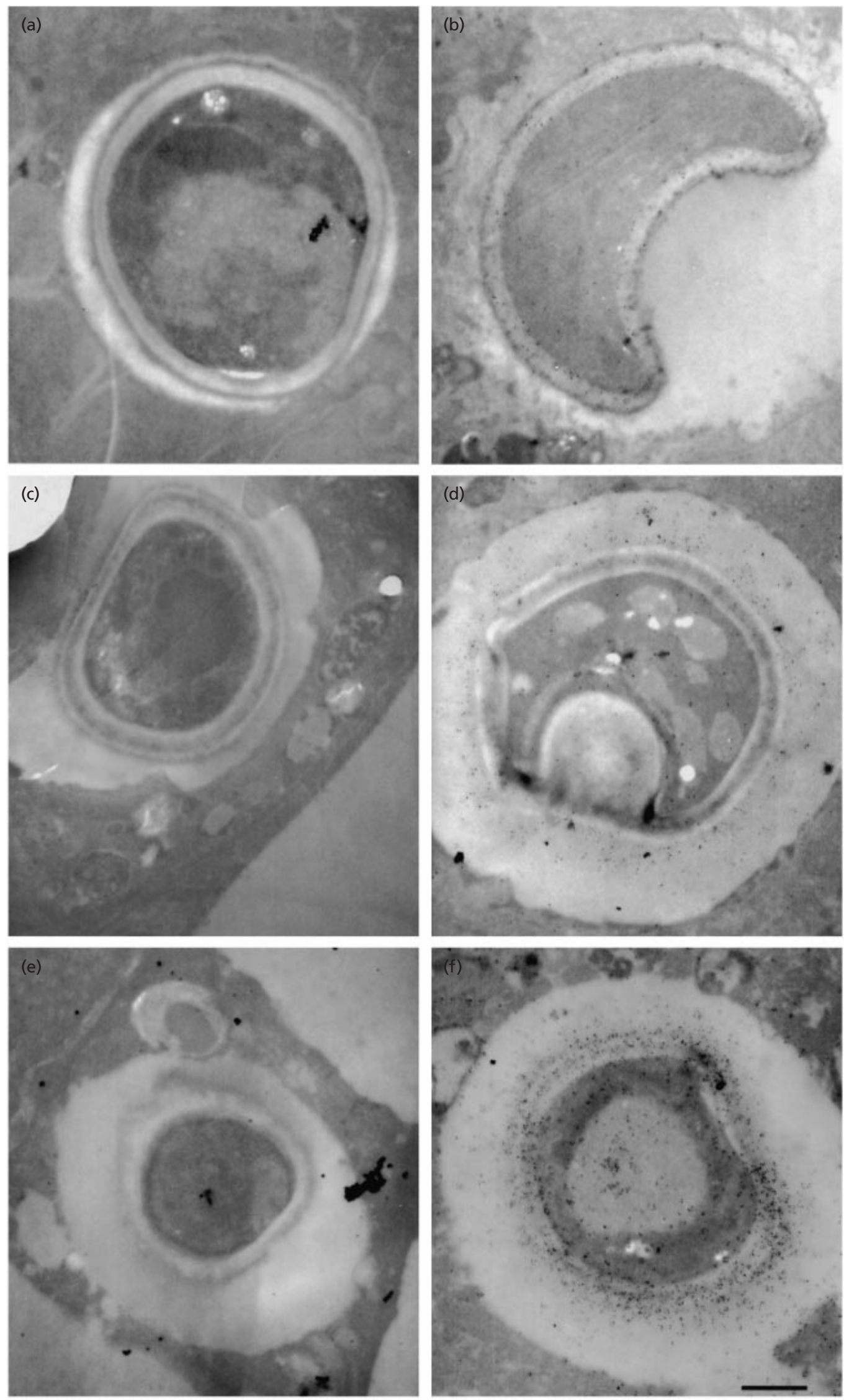

Fig. 5. For legend see facing page. 
5 min after infection may reflect improved preservation of the cell wall structure in lung tissue in a manner similar to that seen for capsule architecture (Feldmesser et al., 2000b). Regardless of the explanation, this difference in cell wall thickness between in vitro yeast cells and those in tissue obtained 5 min after infection does not affect the conclusions of this study because the relevant comparisons all involved measurements of cells in tissue. Furthermore, all samples were processed in an identical fashion and any errors or artefacts introduced by the sample preparation method should apply equally to all groups being compared. We found little variability in the measurements made between mice within individual experiments, with the exception of C57BL/6 mice studied $28 \mathrm{~d}$ after infection, a time at which these mice have developed a granulomatous immune response. The finding of variability late, but not early, after infection may reflect individual differences in the degree to which mice can control this organism. Further, in tissue obtained $2 \mathrm{~h}$ after infection, there was no difference in the measurements of yeast cells made in C57/BL6 or BALB/c mice. However, a difference was seen in sections obtained from different mouse strains on day 13 or 14 after infection. Since both A/JCr and $129 / \mathrm{SvEv}$ mice are more susceptible to pulmonary cryptococcal infection than are C57BL/6 mice (Feldmesser et al., 1998) (personal observation), more replication of yeast in these mouse strains may result in a relative preponderance of younger yeast cells with thinner cell walls. However, definitive correlation of cell wall thickness with host inflammatory response would require further investigation and is beyond the scope of the present study. We are confident that for strain 24067, the mean cell wall size increases during infection but the generalizability of this observation to other cryptococcal strains is unknown.

The morphology of C. neoformans cells in infected tissue was more heterogeneous than when grown in vitro. Heterogeneity in the morphology of $C$. neoformans cells involved both capsule size and yeast cell size. The emergence of giant cells was a striking observation. These cells, found predominantly in extracellular spaces, were much larger than tissue macrophages. In contrast, cells with smaller capsules were commonly found inside macrophages in well-defined vacuoles. Presumably, the emergence of giant cell forms poses a formidable problem for phagocytic cells since their large size relative to macrophages would preclude ingestion. Giant cryptococcal forms have been reported from two cases of human disease, one isolated from the lung and the other from cerebrospinal fluid (Cruickshank et al., 1973; Love et al., 1985). The paucity of such reports in the literature could result from the lack of histopathological data from primary pulmonary infection in humans, which is seldom symptomatic. However, that such isolates have been described suggests that giant forms have relevance to the pathogenesis of human disease. Morphologic variation within lesions has been described for Paracoccidioides brasiliensis and Histoplasma capsulatum (Restrepo, 2000; Sweany et al., 1962). The mechanism responsible for the generation of this diversity in cellular morphology is not understood, but may involve phenotypic switching, phase growth differences, and/or nutrient differences between in vivo and in vitro conditions (Goldman et al., 1998). The pattern of heterogeneity in yeast cell size varied between C. neoformans strains. Although the mean capsule size increased significantly during the course of infection, not all cells displayed larger capsules and populations of cells with large and small capsules coexisted in tissue. Heterogeneity occurred early in the course of infection and was maintained at all times studied. The emergence of giant forms and the heterogeneity of cell size indicate that the immune system must confront cells with varying characteristics during the course of infection. This variation could contribute to the difficulty inherent in controlling this infection.

Given the present efforts to develop antibody therapy for human cryptococcosis and the variability inherent in C. neoformans cells from chronically infected mice, we evaluated whether the epitope recognized by the protective $\mathrm{mAb} 2 \mathrm{H} 1$ was found at all stages of infection. $\mathrm{mAb} 2 \mathrm{H} 1$ bound to the capsule of yeast cells at all times of infection, implying that epitope loss is not a consequence of yeast cell heterogeneity. During the course of this study, we noted that some antibody staining occurred intracellularly. Since very little is known about the location of capsule synthesis in C. neoformans (Doering, 2000), we investigated the location of $\mathrm{mAb}$ reactive epitope in the yeast cell. Though previous studies by conventional freeze-etching (Takeo et al., 1973) and quick freeze-deep etching methods (Sakaguchi et al., 1993) have suggested that precursors are synthesized in cytoplasmic vacuoles or in the particleaccumulating layer of the cell wall, no definitive evidence associates the capsule synthesis machinery with the cell wall. In this study, immunogold labelling with $\mathrm{mAb}$ to GXM demonstrated the presence of the epitope not only in the capsule, but also in the cryptococcal cell wall and cytoplasm, where it appeared to be localized primarily to membrane-bound vacuolar structures. Capsule components containing the epitope recognized by $\mathrm{mAb} 2 \mathrm{H} 1$ may be synthesized intracellularly and exported through the cell wall, possibly in the small vesicles described by Sakaguchi et al. (1993). Further confirmation of this finding will require the identification of markers for cryptococcal vacuoles. These results provide the first direct evidence that capsule synthesis occurs, at least in part, intracellularly.

Among the two serotype D strains $(24067$ and 3501) studied for $\mathrm{mAb}$ binding, we noted qualitative and quantitative differences in the antibody binding pattern.

Fig. 5. Immunogold labelling of strains Cap 67 and 3501 from murine lung $24 \mathrm{~h}$ after infection. (a, b) Strain Cap 67 incubated with PC-140 (IgM control) (a) or mAb 13F1 (b); (c-f) strain 3501 incubated with IgG1 (c), mAb 2H1 (d), mAb PC140 (e) or mAb $13 F 1$ (f). Only rare gold particles are present in control sections $(a, c, e) . B a r, 1 \mu \mathrm{m}$. 
We attribute this finding to subtle differences in GXM structure between strains. Previous studies of yeast cells grown in vitro have shown both significant differences in capsular polysaccharide within a serotype (Small et al., 1986) and heterogeneity within serotypes in the expression of epitopes reactive with mAbs (Spiropulu et al., 1989). GXM structure is notoriously variable among strains and even individual strains can produce different types of GXM depending on the phenotype (Fries et al., 1999).

We unexpectedly found that the cell wall of Cap 67 labelled with $\mathrm{mAb} 13 \mathrm{~F} 1$, though not $\mathrm{mAbs} 2 \mathrm{H} 1$ or $12 \mathrm{~A} 1$. All three mAbs were generated from the spleen of the same GXM-tetanus toxoid immunized mouse. mAbs 12A1 and 13F1 were derived from the same B cell clone (Mukherjee et al., 1993), but differ in fine specificity, binding pattern on intact yeast cells, and protective efficacy (Mukherjee et al., 1993, 1995). Though the mechanisms and genes involved in capsular synthesis are current areas of study for several investigators (Chang et al., 1996; Doering, 1999), the molecular basis for the absence of capsule in this mutant is unknown (Fromtling et al., 1982; Jacobson et al., 1982). The present study shows that the epitope recognized by $\mathrm{mAb} 13 \mathrm{~F} 1$ is produced by this mutant, though labelling was less intense than in its isogenic parent strain. The defect in this mutant may lie, in part, in its ability to export this polysaccharide component through the cell wall, though a little label was found in adjacent tissue, suggesting that this is not the case. However, the epitope recognized by mAbs $2 \mathrm{H} 1$ and 12A1, which have similar, if not identical, fine specificity, was not found in Cap 67, suggesting that synthesis of the component of GXM that forms the epitope for these mAbs is defective. This result raises the tantalizing possibility that the epitopes recognized by the mAbs 12A1 and 13F1 reside in different GXM molecules, a finding that would imply that more than one type of GXM molecule is produced by some strains of C. neoformans.

In summary, our study demonstrates that murine $C$. neoformans infection is a highly dynamic process whereby the morphological characteristics of yeast cells differ as a function of the age of infection. We noted significant differences between yeast cells studied after growth in vitro and the population of yeast cells that emerges in tissue during chronic infection. Although it has been recognized for several decades that infection results in morphological changes highlighted by increased capsule size and cell wall thickness, the occurrence of other changes in cellular characteristics is not widely recognized.

\section{ACKNOWLEDGEMENTS}

M.F. is supported by NIH grant AI01341. A.C. is supported by NIH grants AI22774, AI13342, HL59842 and a Burroughs Wellcome Developmental Therapeutics Award.

We thank Jorge Bermudez for assistance with histopathology, and Clemen Cayetano and Valentin Storovoytov for assistance with electron microscopy. We also thank Gregory Serdahl, without whose assistance this work could not have been completed.

\section{REFERENCES}

Al-Doory, Y. (1971). The ultrastructure of Cryptococcus neoformans. Sabouraudia 9, 113-118.

Casadevall, A. \& Perfect, J. R. (1998). Cryptococcus neoformans. Washington, DC: American Society for Microbiology.

Casadevall, A., Cleare, W., Feldmesser, M. \& 12 other authors (1998). Characterization of a murine monoclonal antibody to Cryptococcus neoformans polysaccharide that is a candidate for human therapeutic studies. Antimicrob Agents Chemother 42, 1437-1446.

Cassone, A., Simonetti, N. \& Strippoli, V. (1974). Wall structure and bud formation in Cryptococcus neoformans. Arch Microbiol 95, 205-212.

Chang, Y. C., Penoyer, L. A. \& Kwon-Chung, K. J. (1996). The second capsule gene of Cryptococcus neoformans, CAP64, is essential for virulence. Infect Immun 64, 1977-1983.

Cruickshank, J. G., Cavill, R. \& Jelbert, M. (1973). Cryptococcus neoformans of unusual morphology. Appl Microbiol 25, 309-312.

Currie, B. P. \& Casadevall, A. (1994). Estimation of the prevalence of cryptococcal infection among patients infected with the human immunodeficiency virus in New York City. Clin Infect Dis 19, 1029-1033.

Doering, T. L. (1999). A unique alpha-1,3 mannosyltransferase of the pathogenic fungus Cryptococcus neoformans. J Bacteriol 181, $5482-5488$.

Doering, T. L. (2000). How does Cryptococcus get its coat? Trends Microbiol 8, 547-553.

Feldmesser, M. \& Casadevall, A. (1997). Effect of serum IgG1 to Cryptococcus neoformans glucuronoxylomannan on murine pulmonary infection. J Immunol 158, 790-799.

Feldmesser, M., Casadevall, A., Kress, Y., Spira, G. \& Orlofsky, A. (1997). Eosinophil-Cryptococcus neoformans interactions in vivo and in vitro. Infect Immun 65, 1899-1907.

Feldmesser, M., Kress, Y. \& Casadevall, A. (1998). Effect of antibody to capsular polysaccharide on eosinophilic pneumonia in murine infection with Cryptococcus neoformans. J Infect Dis 177, 1639-1646.

Feldmesser, M., Kress, Y., Novikoff, P. \& Casadevall, A. (2000a). Cryptococcus neoformans is a facultative intracellular pathogen in murine pulmonary infection. Infect Immun 68, 4225-4237.

Feldmesser, M., Rivera, J., Kress, Y. \& Casadevall, A. (2000b). Antibody interactions with the capsule of Cryptococcus neoformans. Infect Immun 68, 3642-3650.

Franzot, S. P., Salkin, I. F. \& Casadevall, A. (1999). Cryptococcus neoformans var. grubii: separate varietal status for Cryptococcus neoformans serotype A isolates. J Clin Microbiol 37, 838-840.

Fries, B. C., Goldman, D. L., Cherniak, R., Ju, R. \& Casadevall, A. (1999). Phenotypic switching in Cryptococcus neoformans results in changes in cellular morphology and glucuronoxylomannan structure. Infect Immun 67, 6076-6083.

Fromtling, R. A., Shadomy, H. J. \& Jacobson, E. S. (1982). Decreased virulence in stable, acapsular mutants of Cryptococcus neoformans. Mycopathologia 79, 23-29.

Goldman, D. L., Fries, B. C., Franzot, S. P., Montella, L. \& Casadevall, A. (1998). Phenotypic switching in the human pathogenic fungus Cryptococcus neoformans is associated with changes in virulence and pulmonary inflammatory response in rodents. Proc Natl Acad Sci US A 95, 14967-14972. 
Jacobson, E. S. \& Tingler, M. J. (1994). Strains of Cryptococcus neoformans with defined capsular phenotypes. J Med Vet Mycol 32, 401-404.

Jacobson, E. S., Ayers, D. J., Harrell, A. C. \& Nicholas, C. C. (1982). Genetic and phenotypic characterization of capsule mutants of Cryptococcus neoformans. J Bacteriol 150, 1292-1296.

Levitz, S. M. (1991). The ecology of Cryptococcus neoformans and the epidemiology of cryptococcosis. Rev Infect Dis 13, 1163-1169.

Liu, L., Wakamatsu, K., Ito, S. \& Williamson, P. R. (1999). Catecholamine oxidative products, but not melanin, are produced by Cryptococcus neoformans during neuropathogenesis in mice. Infect Immun 67, 108-112.

Love, G. L., Boyd, G. D. \& Greer, D. L. (1985). Large Cryptococcus neoformans isolated from brain abscess. J Clin Microbiol 22, 1068-1070.

Mitchell, T. G. \& Perfect, J. R. (1995). Cryptococcosis in the era of AIDS - 100 years after the discovery of Cryptococcus neoformans. Clin Microbiol Rev 8, 515-548.

Mochizuki, T., Tanaka, S. \& Watanabe, S. (1987). Ultrastructure of the mitotic apparatus in Cryptococcus neoformans. J Med Vet Mycol 25, 223-233.

Mukherjee, J., Casadevall, A. \& Scharff, M. D. (1993). Molecular characterization of the humoral responses to Cryptococcus neoformans infection and glucuronoxylomannan-tetanus toxoid conjugate immunization. J Exp Med 177, 1105-1116.

Mukherjee, J., Nussbaum, G., Scharff, M. D. \& Casadevall, A. (1995). Protective and nonprotective monoclonal antibodies to Cryptococcus neoformans originating from one B cell. J Exp Med 181, 405-409.

Nosanchuk, J. D., Valadon, P., Feldmesser, M. \& Casadevall, A. (1999). Melanization of Cryptococcus neoformans in murine infection. Mol Cell Biol 19, 745-750.
Restrepo, A. (2000). Morphological aspects of Paracoccidioides brasiliensis in lymph nodes: implications for the prolonged latency of paracoccidioidomycosis? Med Mycol 38, 317-322.

Sakaguchi, N., Baba, T., Fukuzawa, M. \& Ohno, S. (1993). Ultrastructural study of Cryptococcus neoformans by quickfreezing and deep-etching method. Mycopathologia 121, 133-141.

Small, J. M., Mitchell, T. G. \& Wheat, R. W. (1986). Strain variation in composition and molecular size of the capsular polysaccharide of Cryptococcus neoformans serotype A. Infect Immun 54, 735-741.

Spiropulu, C., Eppard, R. A., Otteson, E. \& Kozel, T. R. (1989). Antigenic variation within serotypes of Cryptococcus neoformans detected by monoclonal antibodies specific for the capsular polysaccharide. Infect Immun 57, 3240-3242.

Sweany, H. C., Gorelick, D., Coller, F. C. \& Jones, J. L. (1962). Pathology and some diagnostic features of histoplasmosis in patients entering a Missouri hospital. The ' $\mathrm{B}$ ' group. Dis Chest $\mathbf{4 2}$, 128-150.

Takeo, K., Uesaka, I., Uehira, K. \& Nishimura, M. (1973). Fine structure of Cryptococcus neoformans grown in vivo as observed by freeze-etching. J Bacteriol 113, 1449-1454.

Thammana, P. \& Scharff, M. D. (1983). Immunoglobulin heavy chain class switch from IgM to $\operatorname{IgG}$ in a hybridoma. Eur $J$ Immunol 13, 614-619.

Wang, Y. \& Casadevall, A. (1994). Susceptibility of melanized and nonmelanized Cryptococcus neoformans to nitrogen- and oxygen-derived oxidants. Infect Immun 62, 3004-3007.

Zuger, A., Louie, E., Holzman, R. S., Simberkoff, M. S. \& Rahal, J. J. (1986). Cryptococcal disease in patients with the acquired immunodeficiency syndrome. Ann Intern Med 104, 234-240.

Received 16 January 2001; revised 17 April 2001; accepted 4 May 2001 